\title{
Effect of a low-glycaemic index-low-fat-high protein diet on the atherogenic metabolic risk profile of abdominally obese men
}

\author{
Jean G. Dumesnil ${ }^{1,2}$, Jacques Turgeon ${ }^{1,2,3}$, Angelo Tremblay ${ }^{2,5}$, Paul Poirier ${ }^{1,2}$, Marcel Gilbert ${ }^{1,2}$, \\ Louise Gagnon $^{1,2}$, Sylvie St-Pierre ${ }^{2,5}$, Caroline Garneau ${ }^{1,3}$, Isabelle Lemieux ${ }^{1,4}$, Agnès Pascot ${ }^{1,4}$, \\ Jean Bergeron ${ }^{4}$ and Jean-Pierre Després ${ }^{1,4}$ \\ ${ }^{1}$ Québec Heart Institute, Laval Hospital Research Center, Québec, Canada \\ ${ }^{2}$ Faculty of Medicine, Laval University, Québec, Canada \\ ${ }^{3}$ Faculty of Pharmacy, Laval University, Québec, Canada \\ ${ }^{4}$ Lipid Research Center, CHUQ Research Center, Québec, Canada \\ ${ }^{5}$ Division of Kinesiology, Department of Preventive and Social Medicine, Laval University, Québec, Canada
}

(Received 29 October 1999 - Revised 14 May 2001 - Accepted 28 May 2001)

\begin{abstract}
It has been suggested that the current dietary recommendations (low-fat-high-carbohydrate diet) may promote the intake of sugar and highly refined starches which could have adverse effects on the metabolic risk profile. We have investigated the short-term (6-d) nutritional and metabolic effects of an ad libitum low-glycaemic index-low-fat-high-protein diet (prepared according to the Montignac method) compared with the American Heart Association (AHA) phase I diet consumed ad libitum as well as with a pair-fed session consisting of the same daily energy intake as the former but with the same macronutrient composition as the AHA phase I diet. Twelve overweight men (BMI 33.0 $(\mathrm{SD} 3 \cdot 5) \mathrm{kg} / \mathrm{m}^{2}$ ) without other diseases were involved in three experimental conditions with a minimal washout period of 2 weeks separating each intervention. By protocol design, the first two conditions were administered randomly whereas the pair-fed session had to be administered last. During the ad libitum version of the AHA diet, subjects consumed 11695.0 (SD 1163.0) $\mathrm{kJ} / \mathrm{d}$ and this diet induced a $28 \%$ increase in plasma triacylglycerol levels (1.77 (SD 0.79) v. 2.27 (SD 0.92) $\mathrm{mmol} / \mathrm{l}, P<0.05)$ and a $10 \%$ reduction in plasma HDL-cholesterol concentrations (0.92 (SD 0.16) v. 0.83 (SD 0.09) $\mathrm{mmol} / \mathrm{l}$, $P<0 \cdot 01)$ which contributed to a significant increase in cholesterol:HDL-cholesterol ratio $(P<0 \cdot 05)$, this lipid index being commonly used to assess the risk of coronary heart disease. In contrast, the lowglycaemic index-low-fat-high-protein diet consumed ad libitum resulted in a spontaneous $25 \%$ decrease $(P<0 \cdot 001)$ in total energy intake which averaged $8815 \cdot 0(\mathrm{SD} 738 \cdot 0) \mathrm{kJ} / \mathrm{d}$. As opposed to the AHA diet, the low-glycaemic index-low-fat-high-protein diet produced a substantial decrease $(-35 \%)$ in plasma triacylglycerol levels $(2.00$ (SD 0.83) v. 1.31 (SD 0.38) $\mathrm{mmol} / \mathrm{l}, P<0 \cdot 0005)$, a significant increase $(+1.6 \%$ ) in LDL peak particle diameter (251 (SD 5) v. 255 (SD 5) $\AA, P<0 \cdot 02$ ) and marked decreases in plasma insulin levels measured either in the fasting state, over daytime and following a $75 \mathrm{~g}$ oral glucose load. During the pair-fed session, in which subjects were exposed to a diet with the same macronutrient composition as the AHA diet but restricted to the same energy intake as during the low-glycaemic index-low-fat-high-protein diet, there was a trend for a decrease in plasma HDL-cholesterol levels which contributed to the significant increase in cholesterol:HDLcholesterol ratio noted with this condition. Furthermore, a marked increase in hunger $(P<0 \cdot 0002)$ and a significant decrease in satiety $(P<0.007)$ were also noted with this energy-restricted diet. Finally, favourable changes in the metabolic risk profile noted with the ad libitum consumption of the low-glycaemic index-low-fat-high-protein diet (decreases in triacyglycerols, lack of increase in cholesterol:HDL-cholesterol ratio, increase in LDL particle size) were significantly different from the response of these variables to the AHA phase I diet. Thus, a low-glycaemic index-low-fat-highprotein content diet may have unique beneficial effects compared with the conventional AHA diet for the treatment of the atherogenic metabolic risk profile of abdominally obese patients. However, the present study was a short-term intervention and additional trials are clearly needed to document the long-term efficacy of this dietary approach with regard to compliance and effects on the metabolic risk profile.
\end{abstract}

Low-glycaemic index diet: Atherogenesis: Abdominal obesity: Dietary interventions

\footnotetext{
Abbreviation: AHA, American Heart Association.

*Corresponding author: Dr Jean G. Dumesnil, fax +1 418656 4562, email medjgd@ hermes.ulaval.ca
} 
Obesity has reached epidemic proportions in affluent societies and its increasing prevalence in developing countries is a source of concern (Foreyt \& Goodrich, 1995; World Health Organization, 1998). Several epidemiological and metabolic studies published over the last 20 years have emphasized that the subgroup of overweight or obese individuals with an excess of abdominal fat (for reviews, see Després et al. 1990; Kissebah \& Krakower, 1994; Björntorp, 1998) are particularly at high risk not only of developing type 2 diabetes but also CHD. Indeed, studies using computed tomography to assess abdominal fat accumulation have shown that it is the amount of adipose tissue located in the abdominal cavity (the so-called intraabdominal or visceral adipose tissue) that is the critical correlate of atherothrombotic metabolic complications likely to be found in obese patients (Després et al. 1990; Després, 1994; Kissebah \& Krakower, 1994).

Despite the fact that viscerally obese patients are not characterized by major increases in plasma cholesterol or LDL-cholesterol levels (Després, 1994), we have reported that these patients often show a cluster of atherogenic metabolic alterations which include hyperinsulinaemia, elevated apolipoprotein B levels and an increased proportion of small, dense LDL particles (Tchernof et al. 1996). As this atherogenic triad of non-traditional risk variables may be found even among normocholesterolaemic, normotensive and non-diabetic individuals, we have suggested that the high CHD risk associated with the presence of this metabolic triad (hyperinsulinaemia, elevated apolipoprotein B, small, dense LDL) in viscerally obese patients was not adequately appreciated by most physicians (Lamarche et al. 1998). Thus, it is important to develop therapeutic approaches aimed at the improvement of the metabolic risk profile of these high-risk viscerally obese patients. In this regard, a high-complex carbohydrate-low-fat diet has often been advocated (Jeffry et al. 1995; Raben et al. 1995; Siggaard et al. 1996) as a relevant approach to induce weight loss.

Unfortunately, the obese patient's compliance to a lowfat-high-complex carbohydrate diet is often a problem since this population has been shown to have a preference for fat and, indeed, is constantly exposed to highly processed foods which are rich in fat and simple sugars (Drewnowski \& Greenwood, 1983; Drewnowski et al. 1992). Moreover, the recommendation of a low-fat-highcarbohydrate diet may even promote the consumption of sugar and highly refined starches which may lead to obesity and dyslipidaemia, especially among insulin-resistant individuals (Katan et al. 1997; Reaven, 1997; Willett, 1998). Thus, the challenge is to develop a palatable diet which would be low in refined sugar and starches and which would generate enough satiety so that patients could tolerate a reduced energy intake with less discomfort than our current dietary recommendations (Health and Welfare Canada, 1990). In this context, some popular regimens have claimed long-term success for weight loss and increased levels of satiety using a diet based on the ad libitum intake of foods with a low glycaemic index and a higher protein content (Montignac, 1994). However, there have been very few scientific investigations to test the efficacy and safety of these diets which should for the time being limit their widespread use. The present study was thus undertaken to investigate the nutritional and metabolic effects of a low glycaemic index-low-fat-high-protein diet as compared with the widely prescribed American Heart Association (AHA) phase 1 diet in abdominally obese men (Krauss et al. 1996).

\section{Subjects and methods}

Twelve healthy male subjects volunteered for the present study following solicitation in the hospital and in local newspapers. To be included in the study, subjects had to be free from metabolic or endocrine diseases requiring pharmacotherapy or dietary management. Subjects also had to have a BMI above $28 \mathrm{~kg} / \mathrm{m}^{2}$. Average age was 47 (SD 11) years whereas mean BMI reached $33 \cdot 0(\operatorname{SD~} 3 \cdot 5) \mathrm{kg} / \mathrm{m}^{2}$. As abdominal obesity is highly prevalent among men, this selection approach led to the inclusion of abdominally obese subjects as the average waist circumference reached $117 \cdot 4$ (SD 8.4) $\mathrm{cm}$. The project was approved by the Laval Hospital Ethics Review Committee and all subjects gave informed written consent to participate to the study.

Subjects were exposed to three 6-d experimental dietary conditions and were assigned at random to diets 1 and 2 whereas they were exposed last to diet 3 since its energy content had to match that of diet 2 which had never been documented. A minimal wash-out period of 2 weeks separated the three experimental periods during which subjects were told to consume their usual diet. Dietary condition 1 was the AHA phase I diet (Krauss et al. 1996) in which subjects consumed ad libitum a reduced-fat diet (30\% energy from fat, $55 \%$ energy from carbohydrates, $15 \%$ from proteins). The second regimen was a lowglycaemic index-low-fat-high-protein diet based on the method proposed by Montignac (1994). Briefly, this is an ad libitum diet in which menus are designed so that carbohydrates with a glycaemic index above 55 are excluded. Moreover, during meals in which significant amounts of fat are consumed, the glycaemic index of carbohydrates is maintained below 20 whereas proteins can be served at any time and indiscriminately with either fats or carbohydrates. In addition, we designed the menus so that the fat content would tend to approximate $30 \%$ energy intake but without knowing what the exact content would be since the foods composing the menu were served ad libitum. The third regimen was a pair-feeding condition during which subjects' intake of energy was the same as that with the ad libitum dietary condition 2. However, the macronutrient composition of the diet was the same as for the AHA phase I diet. Examples of the menu offered to study subjects on each dietary condition of the protocol and their respective estimated glycaemic index values are shown in the Appendix.

Subjects consumed all their meals in the metabolic ward of the hospital. They had the possibility to eat snacks when exposed to diets 1 and 2 but their energy intake was provided by the three fixed meals in the pair-fed condition since the energy intake was restricted by design. Foods were weighed before each meal and, as well, residual foods were weighed after each meal to determine the amount of food consumed. The subjects were tested in a metabolic ward 
where they were eating ad libitum each meal during the 6-d observation period. Subjects were instructed not to eat foods prepared outside the laboratory during the experimental periods. Foods were offered according to a predetermined menu for which the energy content largely exceeded what a subject could eat. The Canadian Nutrient File (Health and Welfare Canada, 1990) was used to calculate the energy and macronutrient intake. Desire to eat and hunger were rated every day using a $150 \mathrm{~mm}$ visual analogue scale immediately before and after the ingestion of the lunch and the dinner for the three 6-d experimental conditions (Doucet et al. 2000).

Subjects were weighed and their waist and hip circumferences measured before and after each experimental condition. The initial body weights were 101.7 (SD 11.9) $\mathrm{kg}, 102.2$ (SD 11.9) $\mathrm{kg}$ and 99.7 (SD 12.4) $\mathrm{kg}$ for the regimens 1,2 and 3 respectively and waist circumferences were 114.2 (SD 9.6) $\mathrm{cm}, 114.8$ (SD 9.9) $\mathrm{cm}$ and 111.0 (SD $9 \cdot 4) \mathrm{cm}$ for the regimens 1,2 and 3 respectively. At the beginning and at the end of each experimental period, a blood sample was obtained in the morning before the meal ingestion by venipuncture after a 12 -h overnight fast and a $75 \mathrm{~g}$ oral glucose tolerance test was performed with measurements of plasma glucose and insulin levels. Furthermore, during the last day (day 6) of each experimental period, a permanent venous catheter was inserted and blood samples were taken every hour from 8.00 hours to 20.00 hours $(12 \mathrm{~h})$ for determination of plasma glucose, insulin and triacylglycerol levels. During the last day, blood samples obtained at 8.00 hours, 12.00 hours and 17.00 hours were collected before meals served at these three specific times.

A low-speed centrifugation was performed to isolate plasma, and total cholesterol and triacylglycerol levels were assessed using automated enzymic techniques, as previously described (Moorjani et al. 1987). Plasma HDL-cholesterol concentration was measured after precipitation of apolipoprotein B-containing lipoproteins with heparin-manganese chloride (Albers et al. 1978). Plasma insulin levels were measured with an assay not cross-reacting with pro-insulin as previously described (Després et al. 1996). Plasma apolipoprotein B concentration was determined by the rocket immunoelectrophoretic assay of Laurell (1972) as previously reported (Lamarche et al. 1996). Finally, plasma LDL peak particle diameter was determined by $2-16 \%$ polyacrylamide gradient gel electrophoresis (Tchernof et al. 1996; Lamarche et al. 1997). CV for these assays have been previously reported (Després et al. 1996; Tchernof et al. 1996; Lamarche et al. 1997).

\section{Statistical analyses}

Results in tables are expressed as means and SD whereas those in figures are expressed as means and SEM. Data from energy and macronutrient intakes were analysed using a one-way ANOVA design. A similar statistical approach was used for absolute changes in body weight, waist and hip circumferences. Data from plasma lipid and lipoprotein levels at day 1 and day 7 were analysed using a two-way ANOVA with one factor analysed as a repeated factor. The same statistical method was used to analyse data from hunger and satiety, fasting plasma insulin, apolipoprotein B and LDL peak particle diameter. For all these variables, factors were analysed separately when interaction effects were significant. Time-course determinations of glucose, insulin and triacyglycerol levels were analysed using a twoway design for repeated measures. Comparisons between regimens were performed for each hour as profiles between regimens were significantly different. The same statistical approach was used for data on plasma glucose and insulin levels measured from the oral glucose tolerance test. Statistical parametric models were validated for normality and homogeneity of variance assumptions. A posteriori comparisons between means were obtained using Tukey's technique. Energy intake data were adjusted for energy density of food by covariance analysis. The results were considered as significant with $P$-values $\leq 0 \cdot 05$. Data were analysed using the SAS statistical package program (SAS Institute Inc, Cary, NC, USA).

\section{Results}

Table 1 presents the data on energy and macronutrient and fibre intake during each experimental condition. When subjects consumed the AHA phase I diet ad libitum, total energy intake averaged 11695 (SD 1163) kJ/d. In contrast, although food intake was also ad libitum during the lowglycaemic index-low-fat-high-protein diet (condition 2), total energy intake during this condition averaged only 8815 (SD 738) kJ/d and was thus spontaneously reduced by $25 \%$ in comparison with the AHA phase I ad libitum diet. Table 1 shows that regimen 2 also had a reduced energy density. However, the difference in energy intake between these two regimens persisted after correction for the variance explained by the energy density of food. By experimental design, subjects' food intake during condition 3 was thus restricted in order to individually match their intake while on the low-glycaemic index-low-fat-high-protein diet (condition 2). However, this energy-restricted diet had the same macronutrient composition as the AHA phase I diet (condition 1). Detailed analysis of macronutrient intake revealed that relative lipid intake was not substantially different (approximately 30\%) among the three regimens whereas regimen 2 resulted in an increase in the relative intake of proteins (31 (SD 2) \% v. 15 (SD 1) \%, $P<0.001)$ and a decrease in the relative intake of carbohydrates (37 (SD 5) $\%$ v. 55 (SD 1) \%, $P<0 \cdot 001$ ) in comparison with regimen 1. No major difference was found in the fatty acid composition of the diet with the exception of the relative intake of saturated fat which reached 14 (SD 4) \% on regimen 2. Given that regimens 2 and 3 were characterized by a decrease in total energy intake in comparison with regimen 1 , it is also important to consider the differences in absolute macronutrient intakes. Hence, compared with regimen 1, regimen 2 resulted in a $55 \%$ increase in energy from proteins, a $20 \%$ decrease in energy from fats and a $49 \%$ decrease of energy from carbohydrates, whereas by experimental design, regimen 3 resulted in a $20-25 \%$ decrease in energy for all three macronutrients. The average protein intake during regimen 2 (1.67 (SD 0.24) g/kg body weight) was approximately twice the recommended dietary allowance of $0.86 \mathrm{~g} / \mathrm{kg}$ body weight whereas protein intake 
Table 1. Energy intake, weight of food eaten, energy density and macronutrient intake for the three experimental regimens* (Mean values and standard deviations for twelve men)

\begin{tabular}{|c|c|c|c|c|c|c|}
\hline & \multicolumn{2}{|c|}{$\begin{array}{c}\text { Regimen } 1 \\
\text { (AHA phase I ad libitum) }\end{array}$} & \multicolumn{2}{|c|}{$\begin{array}{c}\text { Regimen } 2 \\
\text { (low-Gl-low-fat-high- } \\
\text { protein ad libitum) }\end{array}$} & \multicolumn{2}{|c|}{$\begin{array}{c}\text { Regimen } 3 \\
\text { (restricted AHA phase I) }\end{array}$} \\
\hline & Mean & SD & Mean & SD & Mean & SD \\
\hline Energy intake (kJ/d) & $11695^{a}$ & 1163 & $8815^{\mathrm{b}} \dagger$ & 738 & $8787^{b}$ & 544 \\
\hline Weight of food $(\mathrm{g} / \mathrm{d})$ & $2244^{a}$ & 244 & $2078^{a}$ & 187 & $1702^{b}$ & 106 \\
\hline Energy density $(\mathrm{kJ} / \mathrm{g})$ & $5 \cdot 25^{a}$ & 0.62 & $4 \cdot 27^{b}$ & 0.51 & $5 \cdot 19^{a}$ & 0.57 \\
\hline Protein (\% energy) & $15^{\mathrm{a}}$ & 1 & $31^{\mathrm{b}}$ & 2 & $16^{\mathrm{c}}$ & 0 \\
\hline Lipid (\% energy) & $30^{\mathrm{a}}$ & 1 & $32^{b}$ & 4 & $30^{\mathrm{a}}$ & 0 \\
\hline Carbohydrate (\% energy) & $55^{\mathrm{a}}$ & 1 & $37^{\mathrm{b}}$ & 5 & $54^{\mathrm{a}}$ & 1 \\
\hline Fibre $(g / d)$ & $26^{a}$ & 3 & $29^{b}$ & 3 & $28^{\mathrm{b}}$ & 2 \\
\hline \multicolumn{7}{|l|}{ Fatty acid composition (\%): } \\
\hline Saturated & $10^{\mathrm{a}}$ & 1 & $14^{\mathrm{b}}$ & 4 & $10^{\mathrm{a}}$ & 1 \\
\hline Monounsaturated & 12 & 1 & 12 & 2 & 12 & 1 \\
\hline Polyunsaturated & $4^{\mathrm{a}}$ & 1 & $3^{b}$ & 0 & $4^{\mathrm{a}}$ & 1 \\
\hline
\end{tabular}

AHA, American Heart Association; GI, glycaemic index.

${ }^{\mathrm{a}, \mathrm{b}, \mathrm{c}}$ Mean values within a row with unlike superscript letters were significantly different, $P<0.05$.

${ }^{*}$ For details of diets and procedures, see pp. 558-559.

† Mean value was significantly different from that of regimen 1 after correction for difference in energy density.

during regimen 3 (0.89 (SD 10) g/kg body weight) was $20 \%$ less than during regimen 1 (1.06 (SD 0.09) $\mathrm{g} / \mathrm{kg}$ body weight) and approximately corresponded to the recommended dietary allowance.

Although regimen 2 resulted in a spontaneous $25 \%$ decrease in total energy intake in comparison with regimen 1 , visual analogue scale questionnaires did not reveal any differences in hunger and desire to eat between these two conditions (Fig. 1). In contrast, regimen 3, which was restricted by design to the same amount of energy as regimen 2 but with the same macronutrient composition as regimen 1, was associated with increases in hunger and desire to eat before meals (Fig. $1 ; P<0.0002$ ) and with decreases in fullness and satiety levels after meals (data not shown, $P<0 \cdot 007)$.

When subjects ate ad libitum the AHA phase I diet, no change in body weight nor in waist and hip circumferences was noted at the end of the 6-d intervention period. In contrast, the low-glycaemic index-low-fat-high-protein diet (regimen 2) induced significant decreases in all three anthropometric indices. On average, weight loss was $2 \cdot 3$ (SD $1.6) \mathrm{kg}(P<0.001)$ and was accompanied by a $3.2($ SD $2 \cdot 3)$ $\mathrm{cm}(P<0.001)$ reduction in waist girth and by a $2.7($ SD 3.0$)$ $\mathrm{cm}$ decrease in hip circumference $(P<0 \cdot 02)$. Regimen 3 also induced significant weight loss $(-1.4$ (SD 0.9$) \mathrm{kg}, P<0.001)$ and a reduction in waist circumference $(-2 \cdot 0(\mathrm{SD} 2 \cdot 2) \mathrm{cm}$, $P<0.02)$ whereas the change in hip girth did not reach statistical significance. Furthermore, these changes were not significantly different from those observed during regimen 2 (data not shown).

The effects of the three regimens on the plasma lipid profile are shown in Table 2. No effects of the three diets on plasma cholesterol levels were noted. However, the ad libitum version of the AHA phase I diet induced a $28 \%$ increase $(P<0.05)$ in fasting triacyglycerol levels which was accompanied by a $10 \%$ reduction in HDL-cholesterol concentrations $(P<0 \cdot 01)$. This decrease contributed to the significant increase in cholesterol:HDL-cholesterol following this regimen. In contrast, the ad libitum low-glycaemic index-low-fat-high-protein diet was associated with a substantial reduction in plasma triacyglycerol levels $(-35 \%, P<0.0005)$ whereas this diet had no effect on plasma HDL-cholesterol levels as well as on other variables. The energy-restricted version of the AHA phase I diet (diet matched to the energy intake consumed during the ad libitum low-glycaemic index-low-fat-high-protein diet) failed to induce any significant beneficial change in any of the lipid variables. Moreover, total cholesterol:HDLcholesterol (a commonly-used index of CHD risk) was significantly increased within a week with regimens 1 and 3 (from 5.42 (SD 1.21) to 5.98 (SD 1.36), $P<0.05$ v. 5.26 (SD 1.57 ) to 5.65 (SD 1.59), $P<0.0001$ ), such deterioration not being observed on the low-glycaemic index-low-fat-highprotein diet (from 5.71 (SD 1.30) to 5.53 (SD 1.28), NS). These changes in the lipoprotein-lipid profile in response to the three diet conditions were tested for significance. It was found that the response (lack of response when appropriate) of plasma triacylglycerols, $\mathrm{HDL}$-cholesterol, $\mathrm{HDL}_{3}$-cholesterol and in cholesterol:HDL-cholesterol to the regimen 2 was significantly different from changes noted in response to the ad libitum consumption of the AHA phase I diet.

Fig. 2 shows the effects of the three dietary interventions on fasting plasma insulin and apolipoprotein B levels as well as on LDL peak particle diameter; these three variables having been suggested to be powerful predictors of the risk of IHD (Lamarche et al. 1998). The AHA phase I diet, either in its ad libitum (condition 1) or hypoenergetic (condition 3) version, failed to induce any significant change in these variables. In contrast, the ad libitum low-glycaemic indexlow-fat-high-protein regimen induced a significant decrease in fasting insulin levels and a significant increase in LDL peak particle diameter whereas there was no change in apolipoprotein B levels following this 6-d experimental condition. Furthermore, the change in LDL size observed with diet condition 2 was significantly greater than for the response of this variable to the dietary condition 1 and condition 3.

Fig. 3 shows the daytime 12-h determinations of plasma 

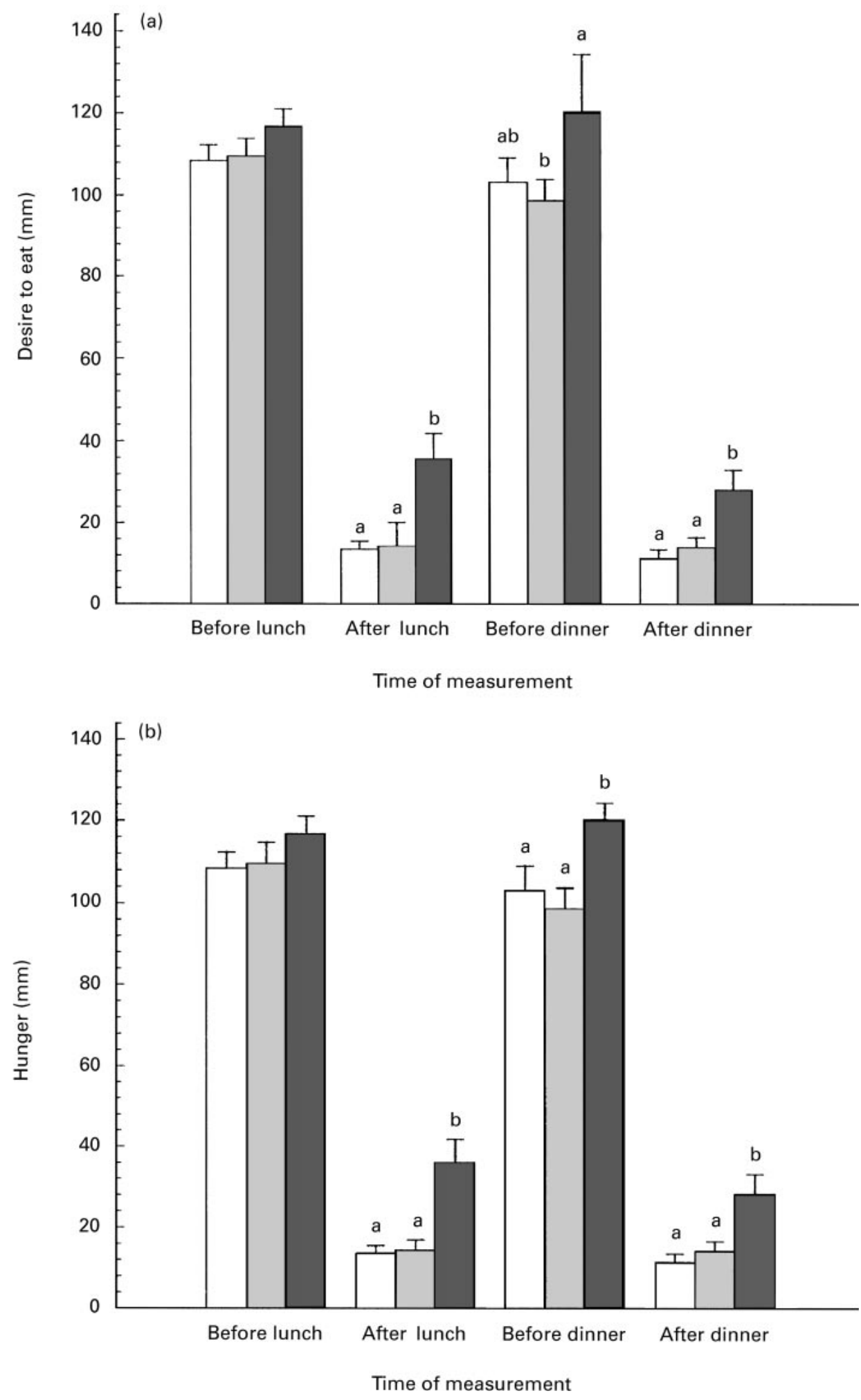

Fig. 1. Mean visual analogue scale ratings for the desire to eat (a) and hunger (b) before and after lunch and dinner for the three dietary regimens. ( $\square$ ), Regimen 1, American Heart Association (AHA) phase I diet ad libitum; ( $\square$ ), regimen 2, low-glycaemic index-low-fat-high protein diet ad libitum; $(\mathbf{\square})$, regimen 3 , restricted AHA phase I diet. Standard errors are represented by vertical bars. ${ }^{\mathrm{a}, \mathrm{b}}$ Mean values for a rating, at a particular time of measurement, with unlike letters were significantly different, $P<0.05$. For details of diets and procedures, see pp. 558-559. 
Table 2. Plasma lipid and lipoprotein levels (mmol/l) of twelve men on three 1-week experimental diets* (Mean values and standard deviations)

\begin{tabular}{|c|c|c|c|c|c|c|c|}
\hline & \multicolumn{2}{|c|}{ Day 1} & \multicolumn{2}{|c|}{ Day 7} & \multicolumn{2}{|c|}{ Change } & \multirow[b]{2}{*}{$P \dagger$} \\
\hline & Mean & SD & Mean & SD & Mean & SD & \\
\hline \multicolumn{8}{|l|}{ Diet 1 (AHA phase I ad libitum) } \\
\hline Triacylglycerols & 1.77 & 0.79 & $2 \cdot 27$ & 0.92 & $0.50^{\mathrm{a}}$ & 0.79 & $<0.05$ \\
\hline Cholesterol & 4.96 & $1 \cdot 27$ & 4.94 & 1.22 & -0.02 & 0.36 & NS \\
\hline LDL-Cholesterol & 3.22 & 1.09 & 3.07 & 1.02 & $-0 \cdot 16$ & 0.45 & NS \\
\hline HDL-Cholesterol & 0.92 & $0 \cdot 16$ & 0.83 & 0.09 & $-0 \cdot 10^{a}$ & $0 \cdot 10$ & $<0.01$ \\
\hline $\mathrm{HDL}_{2}$-Cholesterol & 0.28 & 0.09 & 0.25 & 0.07 & -0.03 & 0.06 & NS \\
\hline $\mathrm{HDL}_{3}$-Cholesterol & 0.64 & $0 \cdot 11$ & 0.57 & 0.09 & $-0.07^{\mathrm{a}}$ & 0.07 & $<0.01$ \\
\hline Cholesterol:HDL-Cholesterol & $5 \cdot 42$ & 1.21 & 5.98 & 1.36 & $0.56^{a}$ & 0.78 & $<0.05$ \\
\hline \multicolumn{8}{|c|}{ Diet 2 (low Gl-low-fat-high-protein ad libitum) } \\
\hline Triacylglycerols & $2 \cdot 00$ & 0.83 & 1.31 & 0.38 & $-0.69^{b}$ & 0.57 & $<0.0005$ \\
\hline Cholesterol & $5 \cdot 25$ & 1.31 & 5.04 & 1.06 & -0.21 & 0.48 & NS \\
\hline LDL-Cholesterol & 3.41 & $1 \cdot 10$ & 3.52 & 0.97 & $0 \cdot 11$ & 0.38 & NS \\
\hline HDL-Cholesterol & 0.93 & 0.15 & 0.92 & $0 \cdot 11$ & $-0.01^{b}$ & $0 \cdot 10$ & NS \\
\hline $\mathrm{HDL}_{2}$-Cholesterol & 0.29 & 0.09 & 0.28 & 0.06 & -0.01 & 0.05 & NS \\
\hline $\mathrm{HDL}_{3}$-Cholesterol & 0.64 & $0 \cdot 11$ & 0.64 & 0.08 & $0.001^{b}$ & 0.08 & NS \\
\hline Cholesterol:HDL-Cholesterol & $5 \cdot 71$ & 1.30 & 5.53 & 1.28 & $-0 \cdot 18^{b}$ & 0.51 & NS \\
\hline \multicolumn{8}{|l|}{ Diet 3 (Restricted AHA phase I) } \\
\hline Triacylglycerols & 1.76 & 0.76 & 1.63 & 0.51 & $-0.13^{b}$ & 0.71 & NS \\
\hline Cholesterol & $5 \cdot 01$ & 1.47 & 5.05 & $1 \cdot 13$ & 0.03 & 0.50 & NS \\
\hline LDL-Cholesterol & 3.24 & 1.26 & 3.38 & 1.09 & 0.14 & 0.54 & NS \\
\hline HDL-Cholesterol & 0.96 & 0.15 & 0.91 & 0.15 & $-0.05^{a, b}$ & 0.08 & NS \\
\hline $\mathrm{HDL}_{2}$-Cholesterol & 0.28 & $0 \cdot 10$ & 0.25 & 0.08 & -0.04 & 0.04 & $<0.01$ \\
\hline $\mathrm{HDL}_{3}$-Cholesterol & 0.68 & $0 \cdot 12$ & 0.67 & $0 \cdot 11$ & $-0.01^{\mathrm{b}}$ & 0.07 & NS \\
\hline Cholesterol:HDL-Cholesterol & $5 \cdot 26$ & 1.57 & 5.65 & 1.59 & $0.39^{\mathrm{a}}$ & 0.23 & $<0.0001$ \\
\hline
\end{tabular}

AHA, American Heat Association; GI, glycaemic index.

${ }^{a, b}$ Mean values for a variable within a column with unlike superscript letters were significantly different, $P<0.05$

* For details of diets and procedures, see pp. 558-559.

$\dagger$ Test for difference from baseline within each experimental diet.

glucose, insulin and triacylglycerol levels performed on day 6 of each experimental condition. There was a similar rise in glucose levels after breakfast during the three diet conditions whereas much smaller increases in glucose levels were noted after lunch and dinner with the lowglycaemic index-low-fat-high-protein diet compared with the two other nutritional conditions (Fig. 3(a)). It is important to point out that meals served during the lowglycaemic index-low-fat-high-protein diet were predominantly carbohydrates and proteins at breakfast and predominantly proteins, lipids and carbohydrates with a very low glycaemic index $(<20)$ at lunch and dinner. Plasma insulin levels during the test day (day 6 on the diet) were markedly reduced with the low-glycaemic index-lowfat-high-protein diet compared with the other two conditions, particularly at lunch and dinner, whereas the hypoenergetic version of the AHA diet (condition 3) showed intermediate levels compared with the other two conditions (Fig. 3(b)). Moreover, the ad libitum version of the AHA diet showed the highest increase in plasma insulin levels in response to the dinner meal. Fig. 3 also shows that a substantial increase in plasma triacylglycerol levels occurred in the daytime with the ad libitum version of the AHA phase I diet. Both the ad libitum consumption of the low-glycaemic index-low-fat-high-protein diet and the restricted intake of AHA phase I diet were associated with lower triacylglycerolaemia throughout the day. However, no difference was observed in the area under the curve of daytime triacylglycerol levels between diet conditions 2 and 3 .
Fig. 4 compares plasma glucose and insulin levels during the glucose tolerance tests performed on day 1 and day 7 of each experimental condition. When this standardized $75 \mathrm{~g}$ glucose challenge was used, no evidence for an improved glucose tolerance was found after 1 week of the Montignac diet or under the energy-restricted AHA phase I diet. For example, the change in glucose area under the curve observed with the regimen 2, was even significantly different from the change noted with the ad libitum Phase I diet. However, the insulin response to the glucose load was significantly decreased after only 1 week on the lowglycaemic index-low-fat-high-protein diet whereas it remained unchanged after 1 week on ad libitum or energy-restricted AHA phase I diets.

\section{Discussion}

The main findings of the present short-term diet trial are that: (1), we were successful in inducing a significant reduction in spontaneous total energy intake; (2), we were able to induce favourable effects on the metabolic risk profile of abdominally obese patients by using an unconventional dietary approach which emphasizes the $\mathrm{ad}$ libitum intake of foods with low glycaemic indices. Some improvements in the metabolic risk profile were also noted within a very short period and without any pharmacological support. Moreover, the low-glycaemic index diet was found to be palatable by subjects and did not produce any undue increase in hunger or decrease in satiety, at least for the 1 -week period during which it was tested. 

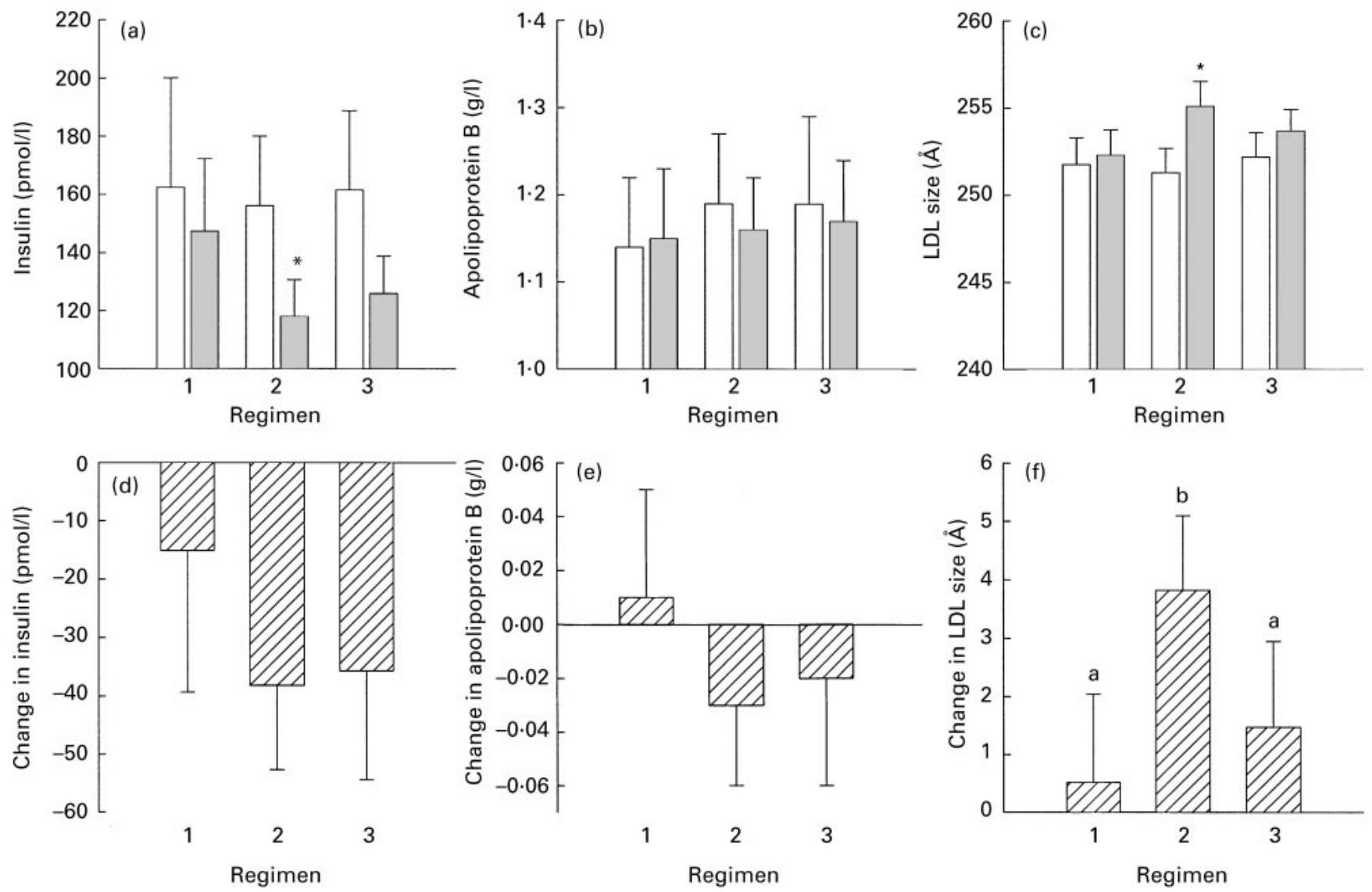

Fig. 2. Mean fasting plasma insulin (a), apolipoprotein B (b) and LDL size (c) before ( $\square$ ) and after ( $\square$ ) each of the three dietary regimens. Mean changes in fasting insulin (d), apolipoprotein B (e) and LDL size (f) in response to the three dietary regimens. Standard errors are represented by vertical bars. *Mean values were significantly different from baseline, $P<0.05$. ${ }^{\text {a,b }}$ Mean responses to diets with unlike letters were significantly different, $P<0.05$. For details of diets and procedures, see p. 558-559.

Although the low-glycaemic index-low-fat-highprotein content diet has enjoyed considerable popular success (Montignac, 1994), especially in Europe, there have been, to our knowledge, few scientific investigations of this method, particularly when offered to subjects on an ad libitum basis. The fact that this diet appeared to be successful while being consumed ad libitum appeared particularly intriguing and was the basic anecdotal observation which led us to undertake the present short-term study. Hence, an important and relatively unexpected result of our study was that this diet produced a substantial (about $25 \%$ ) reduction in energy intake without any change in hunger or satiety, as measured objectively using a visual analogue scale (Doucet et al. 2000). To our knowledge, a reduction in spontaneous energy intake of that magnitude without inducing hunger cannot be achieved without pharmacotherapy, and chronic hunger is a major barrier to compliance when patients are asked to follow a reduced-energy diet.

A significant reduction in weight and decreases in waist and hip circumferences were observed after only 1 week on the low-glycaemic index-low-fat-high-protein diet. This finding should not be overemphasized as initial changes in weight do not necessarily reflect adequately the loss of body fat. The restricted AHA phase I diet, although clamped for energy intake with the low-glycaemic index-low-fat-high-protein diet, also produced weight loss but had a less favourable impact on the metabolic risk profile than the low-glycaemic index diet. The notion that the glycaemic index of foods is important is far from new (Jenkins et al. 1994). Our results are concordant with the numerous studies which have suggested that a diet rich in carbohydrates with a low glycaemic index may be helpful for the management of insulin-resistant or dyslipidaemic patients.

However, the contribution of such a diet in inducing a substantial reduction in spontaneous energy intake is a much less studied issue. Ludwig et al. (1999) have recently reported a $81 \%$ greater voluntary energy intake after a highglycaemic index meal $(5.8 \mathrm{MJ})$ than after a low-glycaemic index meal ( $3 \cdot 2 \mathrm{MJ})$, a finding which is concordant with the results of the present study. In the present study, the lowglycaemic-low-fat-high-protein diet was less energydense than the AHA diet. However, this factor did not entirely explain the reduced energy intake on the low glycaemic index diet since this difference in energy intake remained statistically significant after adjustment for energy density. We are also aware that absence of standardization of the meal frequency of the diet conditions 1 and 2 as compared with condition 3 may have influenced hunger and satiety ratings. Long-term studies will also be necessary to determine whether the spontaneous reduction in energy intake is maintained over time and which are the key factors 

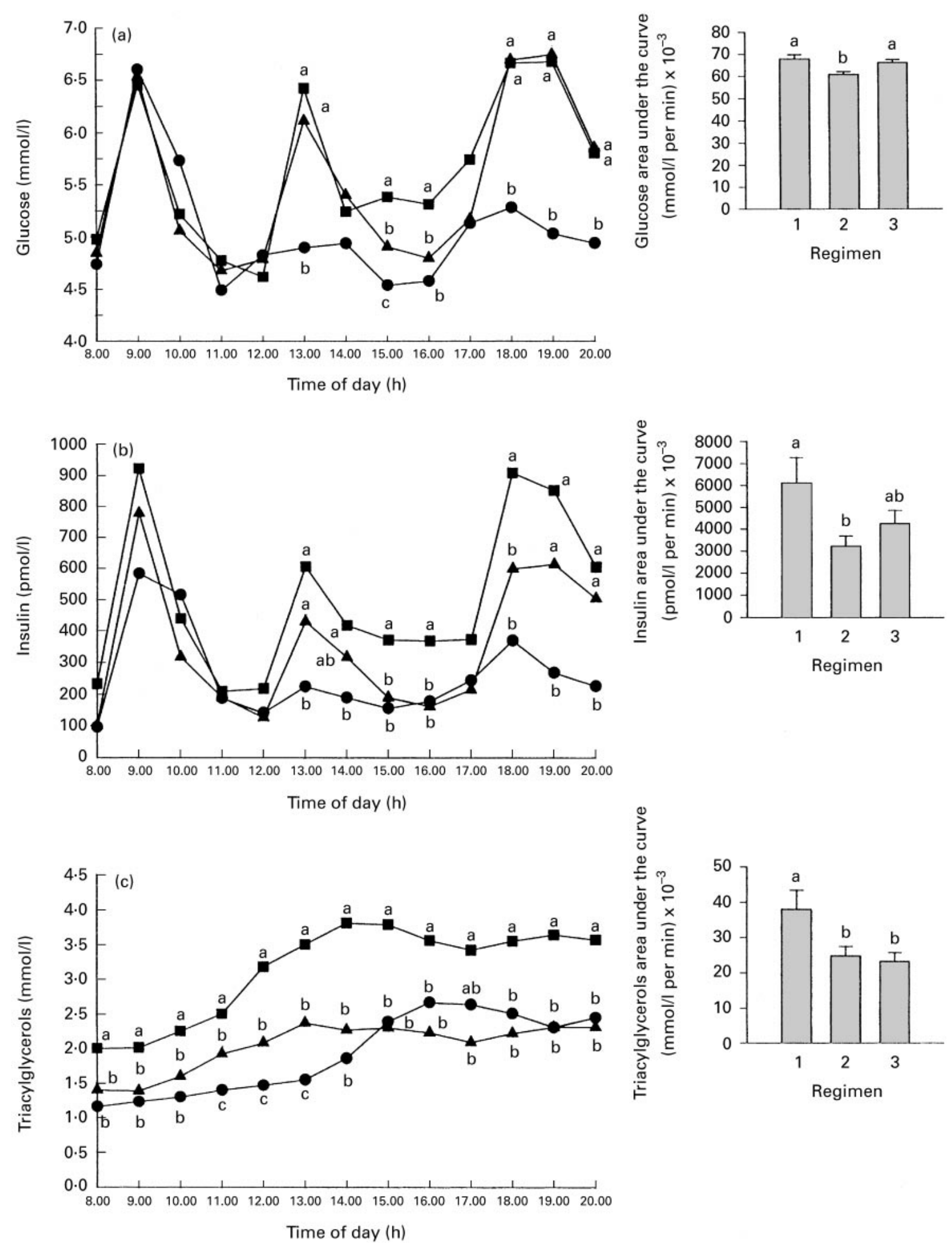

Fig. 3. Mean daytime determinations and areas under the curve of glucose (a), insulin (b) and triacylglycerol levels (c) performed on day 6 of each of the three dietary regimens. ( $\square$ ), Regimen 1, American Heart Association (AHA) phase I diet ad libitum; (•), regimen 2, low-glycaemic index-low-fat-high-protein diet ad libitum; $(\mathbf{\Lambda})$, regimen 3, restricted AHA phase I diet. Standard errors are represented by vertical bars. ${ }_{a, b, c}$ For determinations, mean responses to diets with unlike letters were significantly different, $P<0 \cdot 05$, for areas under the curve, $P<0 \cdot 01$. For details of diets and procedures, see pp. 558-559. 

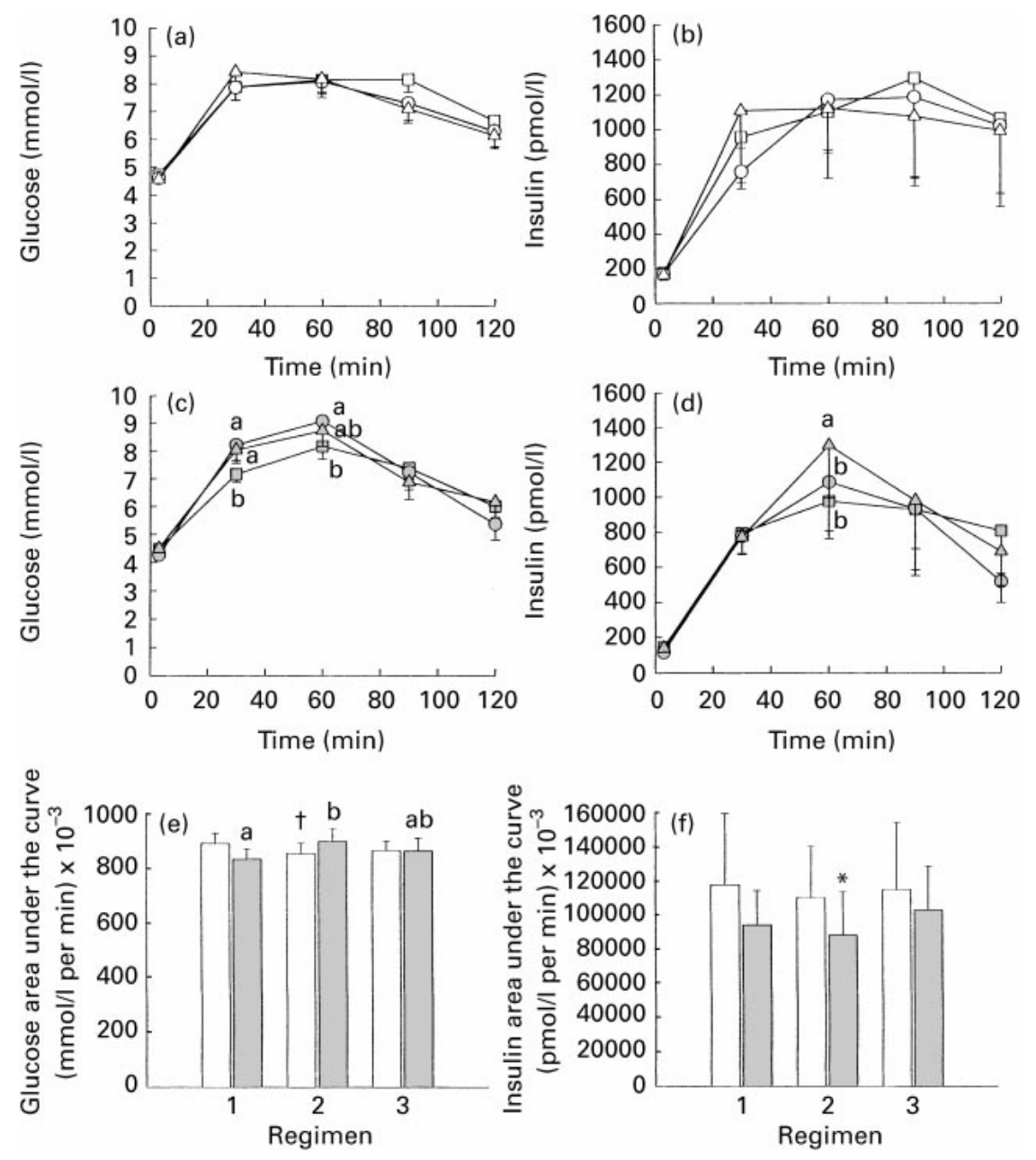

Fig. 4. Mean plasma glucose and insulin levels measured during a $75 \mathrm{~g}$ oral glucose tolerance test performed before and after the three 1-week diets. $(a, c)$, glucose levels at day 1 and 7 respectively; (b, d), insulin levels at days 1 and 7 respectively; (e, f), areas under the curve for plasma glucose and insulin concentrations at days 1 and 7 respectively. ( $\square$ ), Regimen 1, American Heart Association (AHA) phase I diet ad libitum; (๑), regimen 2, low-glycaemic index-low-fat-high-protein diet ad libitum; $(\Delta)$, regimen 3 , restricted AHA phase I diet. Standard errors are represented by vertical bars. *Mean value was significantly different from baseline, $P<0.05$. ${ }^{\mathrm{a}, \mathrm{b}}$ Mean values with unlike letters were significantly different, $P<0.05$. For details of diets and procedures, see pp. 558-559. †Mean change was significantly different from regimen $1, P<0.05$.

explaining the effects of the low-glycaemic index diet on energy intake and eventually on body fatness.

Among the important findings of the present study are the significant and rapid (1 week) effects of the ad libitum lowglycaemic index-low-fat-high-protein diet on plasma triacylglycerol levels and on features of the atherogenic metabolic triad. Recent studies have re-emphasized the importance of hypertriacylglycerolaemia as a relevant marker of an atherogenic dyslipidaemia increasing the risk of CHD (Després \& Lamarche, 1993; Gaudet et al. 1998). The three fish meals of the Montignac diet compared with only one with the AHA diet could have had an impact on triacylglycerol levels, although we doubt it. Moreover, it has been suggested that triacylglycerol concentrations appear to be one of the key elements in the determination of LDL particle size (Tchernof et al. 1996). Accordingly, the substantial (35\%) decrease in plasma triacylglycerol levels observed after only $6 \mathrm{~d}$ of exposure to the low-glycaemic index-low-fat-high-protein diet was associated with a significant increase in LDL particle size. We have recently reported, in a prospective study of middle-aged men, that the simultaneous presence of hyperinsulinaemia, elevated apolipoprotein B levels and small LDL particles was associated with a 20 -fold increased risk of IHD over a 5 -year follow-up period (Lamarche et al. 1998). This cluster of non-traditional alterations was a better predictor of IHD risk than the traditional lipid triad composed of elevated LDL-cholesterol and triacylglycerols and reduced HDLcholesterol (Lamarche et al. 1998). The fact that we were able to favourably alter two of these three components (insulin and LDL size) within only 1 week appears promising and long-term studies are clearly warranted. We had previously shown that apolipoprotein B is very sensitive to abdominal fat accumulation (Després \& Lamarche, 1993) 
and it is likely that the loss of abdominal fat achieved within 1 week was too small and insufficient to reduce apolipoprotein B concentration. The results on plasma insulin levels measured in the fasting state, following the oral glucose load and for $12 \mathrm{~h}$ during daytime on the sixth day of the experimental diets are all concordant with an improved in vivo insulin action and with a reduced insulin secretion produced by the low-glycaemic index-low-fathigh-protein diet. Regarding the effect of the low glycaemic index diet reducing daytime plasma glucose levels, this favourable effect is likely to result from the lower glycaemic load (lower carbohydrate intake and low glycaemic index) of this diet. Such interpretation is supported by the fact that when a standardized glucose challenge was used $(75 \mathrm{~g}$ oral glucose load) there was no evidence for any reduction in the plasma glucose response to the glucose load. Thus, it appears that under conditions mimicking habitual ad libitum intake, the control of appetite and food intake is an important determinant of variations in glycaemia.

Hence, the results of the present study suggest that the low-glycaemic index-low-fat-high-protein diet may represent a relevant approach for the dietary management of patients with abdominal obesity and the insulin resistance syndrome which often characterizes patients with coronary artery disease. When both the widely prescribed AHA phase I and the low-glycaemic index-low-fat-high-protein diets were consumed ad libitum, only the latter diet was associated with unique and significant improvements in several components of the insulin resistance syndrome (fasting and postprandial triacylglycerols and insulin levels and increased LDL particle diameter). To our knowledge, there have been few or no reported ad libitum dietary interventions that have had such marked and rapid effects on the features of the insulin resistance syndrome. Results of the present study are consistent with the favourable metabolic effects of a low-glycaemic index diet reported by Jarvi et al. (1999). As with the two versions of the AHA diet, no short-term effect was observed on LDL cholesterol. It has been suggested that insulin-resistant individuals with hypertriacylglycerolaemia may be more responsive to a low-glycaemic index diet than patients with raised LDLcholesterol (Jenkins et al. 1987). Thus, the possibility cannot be excluded that the low glycaemic index may not be the optimal approach for the management of hypercholesterolaemic, non-obese individuals.

Finally, the potentially deleterious effects of the AHA phase I diet observed in the present study are concordant with concerns previously expressed with this diet (Jeppesen et al. 1997; Katan et al. 1997; Reaven, 1997; Willett, 1998). Indeed, within a week, the ad libitum version of this diet actually had detrimental effects on the fasting lipid profile and produced an increase in triacylglycerol levels, a decrease in HDL-cholesterol and an increase in total cholesterol:HDL-cholesterol. However, the impact of the increased triacylglycerol levels associated with a low-fathigh-carbohydrate diet on the risk of $\mathrm{CHD}$ remains controversial and the impact of such a diet on triacylglycerol levels may be the result of the concomitant variation in the sucrose intake which was not encouraged but not banned in the AHA phase I as opposed to the Montignac diet. However, the AHA phase I diet induced an increase in postprandial triacylglycerol levels, a finding which along with the daytime hyperinsulinaemia suggests a further deterioration of insulin resistance and postprandial hyperlipidaemia, conditions which have been associated with the accumulation of potentially atherogenic chylomicron remnants (Grundy, 1997). Although subjects' diet before this study was not evaluated, these effects are probably due to the fact that the decrease in the amount of fat consumed during the experimental period was compensated by an increase in the total amount of carbohydrates consumed as compared with their usual diet. Again, the increased sucrose content of the AHA phase I diet could be, at least in part, responsible for the deterioration in the metabolic risk factor profile observed with this diet. The hypoenergetic version of the AHA diet did not have the same detrimental effects probably because the total amount of carbohydrates consumed did not increase as compared with their usual intake. The present results are consistent with the common clinical observation that the AHA diet may eventually lower LDL cholesterol but often at the expense of an increase in triacylglycerol levels and a decrease in HDL cholesterol concentration, particularly if there is no concomitant reduction in total energy intake (Katan et al. 1997). Furthermore, it should be kept in mind that the hypoenergetic version of the AHA diet markedly increased hunger and decreased satiety in the present study, and these factors may be major obstacles to long-term compliance. Thus, the present study suggests that the AHA phase I diet may not represent the optimal dietary recommendation for abdominally obese, insulin-resistant and dyslipidaemic patients.

In conclusion, results of the present short-term study indicate that a low-glycaemic index-low-fat-high-protein diet can produce a marked decrease in ad libitum energy intake without increasing hunger or decreasing satiety while having rapid and marked effects on metabolic risk variables. Hence, these results suggest that replacement of dietary lipids by proteins rather than by carbohydrates and the use of carbohydrates with a low glycaemic index should be further explored for the management of men with the features of the insulin resistance dyslipidaemic syndrome. Long-term trials are clearly needed to document the compliance and metabolic response to such an unconventional dietary approach.

\section{Acknowledgements}

Jean-Pierre Després is chair professor of human nutrition and lipidology which is supported by Parke-Davis/WarnerLambert, Provigo and by the Foundation of the Québec Heart Institute. Isabelle Lemieux is recipient of a studentship from the Heart and Stroke Foundation of Canada and Jean Bergeron is a clinical research scholar from the Fonds de la Recherche en Santé du Québec. We also acknowledge Mr. Serge Simard for his expertise in the statistical analyses.

\section{References}

Albers JJ, Warnick GR, Wiebe D, King P, Steiner P, Smith L, Breckenridge C, Chow A, Kuba K, Weidman S, Arnett H, Wood P \& Shlagenhaft A (1978) Multi-laboratory comparison of three 
heparin- $\mathrm{MnCl}_{2}$ precipitation procedures for estimating cholesterol in high-density lipoproteins. Clinical Chemistry 24, $853-856$.

Björntorp P (1998) Abdominal obesity and the development of non-insulin dependent diabetes mellitus. Diabetes and Metabolism Reviews 4, 615-622.

Després JP (1994) Dyslipidemia and obesity. Baillière's Clinical Endocrinology and Metabolism 8, 629-660.

Després JP \& Lamarche B (1993) Effects of diet and physical activity on adiposity and body fat distribution: implications for the prevention of cardiovascular disease. Nutrition Research Reviews 6, 137-159.

Després JP, Lamarche B, Mauriège P, Cantin B, Dagenais GR, Moorjani S \& Lupien PJ (1996) Hyperinsulinemia as an independent risk factor for ischemic heart disease. New England Journal of Medicine 334, 952-957.

Després JP, Moorjani S, Lupien PJ, Tremblay A, Nadeau A \& Bouchard C (1990) Regional distribution of body fat, plasma lipoproteins, and cardiovascular disease. Arteriosclerosis $\mathbf{1 0}$, $497-511$.

Doucet E, Imbeault P, St-Pierre S, Alméras N, Mauriège P, Richard D \& Tremblay A (2000) Appetite after weight loss by energy restriction and a low-fat diet-exercise follow-up. International Journal of Obesity 24, 906-914.

Drewnowski A \& Greenwood MRC (1983) Cream and sugar: human preferences for high-fat foods. Physiology and Behavior 30, 629-633.

Drewnowski A, Krahn DD, Demitrack MA, Nairn K \& Gosnell BA (1992) Taste responses and preferences for sweet high-fat foods: evidence of opioid involvement. Physiology and Behavior 51, $371-379$.

Foreyt J \& Goodrich K (1995) The ultimate triumph of obesity. Lancet 346, 34-35.

Foster-Powell K \& Brand Miller J (1995) International tables of glycemic index. American Journal of Clinical Nutrition 62, 871S-893S.

Gaudet D, Vohl MC, Perron P, Tremblay G, Gagné C, Lesiège D, Bergeron J, Moorjani S \& Després JP (1998) Relationships of abdominal obesity and hyperinsulinemia to angiographically assessed coronary heart disease in men with known mutations in the LDL receptor gene. Circulation 97, 871-877.

Grundy SM (1997) Small, dense LDL, atherogenic dyslipidemias, and the metabolic syndrome. Circulation 95, 1-4.

Health and Welfare Canada (1990) The Canadian Nutrient File. Ottawa: Government of Canada.

Jarvi AE, Karlstrom BA, Granfeldt YE, Bjorck IE, Asp NGL \& Vessby BOH (1999) Improved glycaemic control and lipid profile and normalized fibrinolytic activity on a low-glycaemic index diet in type 2 diabetic patients. Diabetes Care 22, 1-18.

Jeffry RW, Hellerstedt WL, French SA \& Baxter JE (1995) A randomized trial of counselling for fat restriction versus calorie restriction in the treatment of obesity. International Journal of Obesity 19, 132-137.

Jenkins DJ, Jenkins AL, Wolever TM, Vuksan V, Rao AV, Thompson LU \& Josse RG (1994) Low glycaemic index: lente carbohydrates and physiological effects of altered food frequency. American Journal of Clinical Nutrition 59, 706S-709S.

Jenkins DJA, Wolever TMS, Kalmusky J, Guidici S, Giordano C, Patten R, Wong GS, Bird JN, Hall M, Buckley G, Csima A \& Little JA (1987) Low-glycaemic index diet in hyperlipidemia: use of traditional starchy foods. American Journal of Clinical Nutrition 46, 66-71.

Jeppesen J, Schaaf P, Jones C, Zhou M-Y, Ida Chen Y-D \& Reaven GM (1997) Effects of low-fat, high carbohydrate diets on risk factors for ischemic heart disease in postmenopausal women. American Journal of Clinical Nutrition 65, 1027-1033.

Katan MB, Grundy SM \& Willett WC (1997) Beyond low-fat diets. New England Journal of Medicine 337, 563-566.

Kissebah AH \& Krakower GR (1994) Regional adiposity and morbidity. Physiological Reviews 74, 761-811.

Krauss RM, Deckelbaum RJ, Ernst N, Fisher E, Howard BV, Knopp RH, Kotchen T, Lichtenstein AH, McGill HC, Pearson TA, Prewitt TE, Stone NJ, Horn LV \& Weinberg R (1996) Dietary guidelines for healthy American adults. A statement for health professionals from the Nutrition Committee, American Heart Association. Circulation 94, 1795-1800.

Lamarche B, Moorjani S, Lupien PJ, Cantin B, Dagenais GR \& Després JP (1996) Apolipoprotein A-I and B levels and the risk of ischemic heart disease during a five-year follow-up of men in the Québec Cardiovascular Study. Circulation 94, 273-278.

Lamarche B, Tchernof A, Dagenais GR, Cantin B, Lupien PJ \& Després JP (1997) Small, dense LDL particles and the risk of ischemic heart disease. Prospective results from the Québec Cardiovascular Study. Circulation 95, 69-75.

Lamarche B, Tchernof A, Mauriège P, Cantin B, Dagenais GR, Lupien PJ \& Després JP (1998) Fasting insulin and apolipoprotein B levels and low-density lipoprotein particle size as risk factors for ischemic heart disease. Journal of the American Medical Association 279, 1955-1961.

Laurell CB (1972) Electroimmunoassay. Scandinavian Journal Clinical and Laboratory Medicine 124, 23-27.

Ludwig DS, Majzoub JA, Al-Zahrani A, Dallal GE, Blanco I \& Roberts SB (1999) High glycaemic index foods, overeating, and obesity. Pediatrics 103, E26.

Montignac M (1994) Je Mange donc je Maigris, Flammarion. Paris: J'ai lu, collection, pp. 243.

Moorjani S, Dupont A, Labrie F, Lupien PJ, Brun LD, Gagné C, Giguère M \& Bélanger A (1987) Increase in plasma high density lipoprotein concentration following complete androgen blockade in men with prostatic carcinoma. Metabolism 36, 244-250.

Raben A, Linsen ND, Marckmann P, Sandstrom B \& Astrup A (1995) Spontaneous weight loss during 11 weeks ad libitum intake of a low fat/high fiber diet in young normal weight subjects. International Journal of Obesity 19, 916-923.

Reaven GM (1997) Do high carbohydrate diets prevent the development or attenuate the manifestations (or both) of syndrome X? A viewpoint strongly against. Current Opinion in Lipidology 8, 23-27.

Siggaard R, Raben A \& Astrup A (1996) Weight loss during 12 weeks' ad libitum carbohydrate-rich diet in overweight and normal-weight subjects at a Danish work site. Obesity Research 4, 347-356.

Tchernof A, Lamarche B, Prud'homme D, Nadeau A, Moorjani S, Labrie F, Lupien PJ \& Després JP (1996) The dense LDL phenotype: association with plasma lipoprotein levels, visceral obesity and hyperinsulinemia in men. Diabetes Care 19, 629-637.

Willett WC (1998) Dietary fat and obesity: an unconvincing relation. American Journal of Clinical Nutrition 68, 1149-1150.

World Health Organization (1998) Report of a WHO Consultation on Obesity. Obesity: Preventing and Managing the Global Epidemic, Geneva: WHO. 


\section{Appendix}

Examples of menus from each regimen of the protocol and their respective estimated glycaemic index values based on glucose as the reference food*

\begin{tabular}{|c|c|c|c|c|c|}
\hline \multirow{2}{*}{$\frac{\text { Regimen } 1 \text { (AHA phase I ad libitum) }}{\text { Food item }}$} & \multirow[b]{2}{*}{ GI } & \multicolumn{2}{|c|}{$\begin{array}{c}\text { Regimen } 2 \text { (low Gl-low-fat-low-protein ad } \\
\text { libitum) }\end{array}$} & \multicolumn{2}{|c|}{$\begin{array}{c}\text { Regimen } 3 \text { (Restricted } \\
\text { AHA phase I) }\end{array}$} \\
\hline & & Food item & GI & Food item & GI \\
\hline \multicolumn{6}{|l|}{ Breakfast } \\
\hline Wholewheat bread $\dagger$ & $\begin{array}{l}\text { Undetermined, but } \\
\text { probably }<51\end{array}$ & Wholewheat bread $†$ & $\begin{array}{l}\text { Undetermined, but } \\
\text { probably }<51\end{array}$ & Same as $\mathrm{AHA}$ & \\
\hline \multirow[t]{2}{*}{ Bran flakes } & 42 & Unsweetened jam & $\begin{array}{l}\text { Undetermined, but } \\
\text { probably }<51\end{array}$ & & \\
\hline & & Cottage cheese & Low $\ddagger$ & & \\
\hline Coffee or tea & - & Coffee or tea & - & & \\
\hline Milk (2\% fat) & 27 & & & & \\
\hline Cheese or peanut butter & Low & & & & \\
\hline Orange juice & 52 & & & & \\
\hline \multicolumn{6}{|l|}{ Lunch } \\
\hline Tomato and cucumber salad & Low $\ddagger$ & Vegetable salad & Low & Same as $\mathrm{AHA}$ & \\
\hline Salmon & - & Beef steak & - & & \\
\hline White sauce (milk, butter, flour) & Undetermined GI & Yellow waxed beans & Lowł & & \\
\hline White rice & $56 \S$ & Regular cheese & Low $\ddagger$ & & \\
\hline Raspberry granola bars & $66 \S$ & & & & \\
\hline \multicolumn{6}{|l|}{ Dinner } \\
\hline Beet salad & $64 \S$ & Greek salad & Low $\ddagger$ & Same as AHA & \\
\hline White sauce (milk, butter, flour) & Low $\ddagger$ & Chicken breast & - & & \\
\hline Mashed potatoes & $70 \S$ & Green waxed beans & Low $\ddagger$ & & \\
\hline Eggs & - & Regular cheese & Low $\ddagger$ & & \\
\hline Raspberry granola bars & $66 \S$ & & & & \\
\hline \multicolumn{6}{|l|}{ Snacks } \\
\hline Apple muffin & $44 \S$ & Fresh fruits & $36-53 \S$ & & \\
\hline
\end{tabular}

AHA, American Heart Association; GI, glycaemic index.

*For details of diets, see pp. 558-559.

† Made without white flour and without sugar.

‡ Low Gl, no data are available but Gl probably $<30$.

$\S$ GI values from Foster-Powell, \& Brand Miller (1995). 